\title{
PASSION Project: Data Collection in Madagascar and Guinea
}

\author{
Fahafahantsoa Rapelanoro Rabenja, MD, MPH \\ Department of Dermatology, University Hospital Joseph Raseta Befelatanana, Antananarivo, Madagascar
}

\section{Corresponding Author:}

Fahafahantsoa Rapelanoro Rabenja, MD, MPH

Department of Dermatology

University Hospital Joseph Raseta Befelatanana

$3 \mathrm{GHF}+\mathrm{F} 72$

Antananarivo, 101

Madagascar

Phone: 261202222384

Email: frapelanoro@gmail.com

\section{Abstract}

Background: Little data on dermatological conditions presenting on African skin are currently available. This is partly due to the lack of dermatologists in African countries, such as Madagascar and Guinea. There are only 13 dermatologists in Madagascar, or one dermatologist for every 2 million inhabitants. By contrast, the prevalence of common dermatosis is constantly increasing, especially among the pediatric population. According to the World Health Organization, $80 \%$ of these skin problems in Africa are grouped into the following 5 pathologies: atopic dermatitis, dermatophytosis, scabies, impetigo, and insect bites.

Objective: In the face of this dilemma, artificial intelligence (AI) is a better tool to collect data on a national scale. Madagascar began participating in the PASSION project in June 2020 and Guinea began participating in January 2021. They join other countries, like Switzerland, Australia, China, India, and Tanzania, who are also using AI in dermatology. This study mainly aimed to compare the 5 pathologies according to the different phototypes characterizing these countries and to collect cases on a national scale that will form a national database. The aim of the data collection is to add 1000 cases per year to the database.

Methods: To increase the number of cases included in phototypes III to VI, two countries were included. A total of 6 data collection sites were set up in Madagascar and one was set up in Guinea. Patients were recruited during dermatology consultations. All patients presenting the 5 pathologies were included. A total of 3 platforms were used to collect data: my.crf.one, IntelliStream, and Derma2go.

Results: A total of 323 cases are currently included in the database for Madagascar, including 76 cases of scabies, 111 cases of atopic dermatitis, 94 cases of dermatophytosis, 35 cases of impetigo and 11 cases of insect bites. The patients' ages ranged from 2 months to 68 years. A male predominance was noted, with a sex ratio of 1.19 (109 males and 91 females). Phototypes ranged from III to VI. For Guinea, 178 total cases included 32 cases of scabies, 26 cases of atopic dermatitis, 92 cases of dermatophytosis, 3 cases of impetigo, and 25 cases of insect bites. Patients' ages ranged between 1 year and 70 years, with a male predominance, a sex ratio of 1.54 (108 males and 70 females), and a predominance of phototype VI.

Conclusions: AI is a data collection solution in Africa. However, high bandwidth is needed to employ AI.

Conflicts of Interest: None declared.

(iproc 2022;8(1):e36903) doi: $10.2196 / 36903$

\section{KEYWORDS}

pediatric dermatology; artificial intelligence; phototypes 
Edited by T Derrick; this is a non-peer-reviewed article. Submitted 28.01.22; accepted 28.01.22; published 11.02.22.

Please cite as:

Rabenja FR

PASSION Project: Data Collection in Madagascar and Guinea

iproc 2022;8(1):e36903

URL: https://www.iproc.org/2022/1/e36903

doi: $\underline{10.2196 / 36903}$

PMID:

(CFahafahantsoa Rapelanoro Rabenja. Originally published in Iproceedings (https://www.iproc.org), 11.02.2022. This is an open-access article distributed under the terms of the Creative Commons Attribution License (https://creativecommons.org/licenses/by/4.0/), which permits unrestricted use, distribution, and reproduction in any medium, provided the original work, first published in Iproceedings, is properly cited. The complete bibliographic information, a link to the original publication on https://www.iproc.org/, as well as this copyright and license information must be included. 